\title{
Maternal and newborn health services utilization in Jimma Zone, Southwest Ethiopia: a community based cross- sectional study
}

Lelisa Sena Dadi ${ }^{*}$, Melkamu Berhane ${ }^{2}$, Yusuf Ahmed ${ }^{3}$, Esayas Kebede Gudina ${ }^{4}$, Tasew Berhanu ${ }^{5}$, Kyung Hwan Kim , Masrie Getnet ${ }^{1}$ and Muluemabet Abera ${ }^{7}$

\begin{abstract}
Background: Majority of causes of maternal and newborn mortalities are preventable. However, poor access to and low utilization of health services remain major barriers to optimum health of the mothers and newborns. The objectives of this study were to assess maternal and newborn health services utilization and factors affecting mothers' health service utilization.

Methods: A community based cross-sectional survey was carried out on randomly selected mothers who gave birth within a year preceding the survey. The survey was supplemented with key informant interviews of experts/ health professionals. Multivariable logistic model was used to identify factors associated with service utilization. Adjusted odds ratios (AORs) were used to assess the strength of the associations at $p$-value $\leq 0.05$. The qualitative data were summarized thematically.
\end{abstract}

Results: A total of 789 (99.1\% response rate) mothers participated in the study. The proportion of the mothers who got at least one antennal care (ANC) visit, institutional delivery and postnatal care (PNC) were 93.3, 77.4 and 92.0\%, respectively. Three-forth (74.2\%) of the mothers started ANC lately and only $47.5 \%$ of them completed $\mathrm{ANC}_{4}+$ visits. Medium (4-6) family size (AOR: 2.3; 95\% Cl: 1.1, 4.9), decision on ANC visits with husband (AOR: 30.9; 95\% Cl: 8.3, 115.4) or husband only (AOR: 15.3; 95\%Cl: $3.8,62.3$ ) and listening to radio (AOR: $2.5 ; 95 \% \mathrm{Cl}: 1.1,5.6)$ were associated with ANC attendance.

Mothers whose husbands read/write (AOR: 1.6; $95 \%$ Cl: 1.1, 2.), attended formal education (AOR: $2.8 ; 95 \%$ Cl: 1.1, 6.8), have positive attitudes (AOR: 10.2; 95\% Cl: 25.9), living in small (AOR: 3.0; 95\% Cl: 1.2, 7.6) and medium size family (AOR: $2.3 ; 95 \%$ Cl: $1.2,4.1$ ) were more likely to give birth in-health facilities. The proportion of PNC checkups among mothers who delivered in health facilities and at home were 92.0 and 32.5\%, respectively. The key informants mentioned that home delivery, delayed arrival of the mothers, unsafe delivery settings, shortage of skilled personnel and supplies were major obstacles to maternal health services utilization.

Conclusions: Health information communication targeting husbands may improve maternal and newborn health services utilization. In service training of personnel and equipping health facilities with essential supplies can improve the provider side barriers.

Keywords: Antenatal care, Delivery services, Postnatal care, Jimma/Ethiopia

\footnotetext{
* Correspondence: lelisajitu@gmail.com

${ }^{1}$ Department of Epidemiology, Faculty of Public Health, Jimma University,

Jimma, Ethiopia

Full list of author information is available at the end of the article
}

(c) The Author(s). 2019 Open Access This article is distributed under the terms of the Creative Commons Attribution 4.0 International License (http://creativecommons.org/licenses/by/4.0/), which permits unrestricted use, distribution, and reproduction in any medium, provided you give appropriate credit to the original author(s) and the source, provide a link to the Creative Commons license, and indicate if changes were made. The Creative Commons Public Domain Dedication waiver (http://creativecommons.org/publicdomain/zero/1.0/) applies to the data made available in this article, unless otherwise stated. 


\section{Background}

Majority of the causes of maternal and newborn mortalities/morbidities are known to be preventable using basic interventions [1]. Curbing preventable maternal and newborn mortality is critical to achieving the Sustainable Development Goals (SDGs) [2]. In spite of the unreserved efforts made by the government and other partners, the maternal mortality ratio and infant mortality rate remain unacceptably high and among the unachieved Millennium Development Goal (MDGs) targets in Ethiopia. Studies show that the reduction in maternal mortality remains insignificant over the past three decades [3, 4]. It has been estimated that SDG 3.1 can be achieved if coverages of first antenatal care visit $\left(\mathrm{ANC}_{1}\right)$, fourth antenatal care visit $\left(\mathrm{ANC}_{4}\right)$, institutional delivery and skilled birth attendance reach $91,78,81$, and $87 \%$, respectively [5].

A health facility-based study conducted in central Ethiopia [6] revealed that in spite of high $\mathrm{ANC}_{1}$ (89.4\%), institutional delivery (82.4\%) and postnatal care (PNC) within six hours of delivery (74.6\%), below half (46.6\%) and only $14(1.2 \%)$ of the study participants reported to have had three or more ANC and PNC visits, respectively. An earlier community-based study conducted in Northwest Ethiopia [7] also showed that only $12.1 \%$ of the mothers gave birth in health institutions during the 12 months preceding the survey.

Poor access to and low utilization of key interventions due to different socio-cultural and economic factors are still major obstacles to optimum maternal and newborn health $[5,8]$. For instance, a study shows that among mothers who gave birth, only less than a third (32\%) had reported to having attended the recommended $\mathrm{ANC}_{4}+$ visits $[6,9]$. Other studies $[2,10]$ have also shown that women health care utilization is adversely affected by distance to health institutions, related costs, cultural barriers and customs, low status of women, husband disapproval, and low level of health awareness.

Studies conducted in Ethiopia [11], Ghana [12] and Nigeria [13] on Demographic and Health Surveys (DHSs) data also indicated the influence of contextual and individual factors, including maternal age, education, marital age, residence, wealth and access to media on mothers' skilled delivery care utilization. Other studies [14-16] also noted that $\mathrm{ANC}_{4+}$, knowledge of pregnancy danger signs, place of delivery and delivery complications are significantly associated with PNC utilization of mothers. Still, other studies [12, 17, 18] show that maternal health services utilization is influenced by the educational status of the mothers/partners, household wealth, residence/distance to health facilities. On the other hand, service-related factors can greatly influence the health-seeking behavior of the mothers. Studies [19-22] show that perceived quality of services, inconsistent availability of medical supplies and unethical approaches or unavailability of trained care providers adversely affects the choice of place for maternal health services.
For instance, a study conducted at Assela Hospital, central Ethiopia, reported that mothers were dissatisfied due to poor cleanliness and lack of latrines while they were under intrapartum care [23]. Again, a study conducted in Addis Ababa shows that $78.0 \%$ of respondents experienced one or more categories of disrespect and abuse in health centers $(75.3 \%)$ and hospitals $(81.8 \%)$ during their previous visits [24]. Another hospital-based study conducted in Addis Ababa revealed that overall, only 19.0\% of the mothers were satisfied with intrapartum care [25]. A similar study [26] reported that the level of satisfaction with intrapartum care was low. The main unsatisfying factors were poor pain management, lack of client privacy and client-provider communication.

Several studies [27-31] show that maternal health services utilization is influenced by multitude socioeconomic and demographic factors, which vary widely with the local context. According to a multilevel analysis of EDHS of 2011 [32], significant variations in the usage of antenatal and delivery care services were found to be attributed to an array of individual, household and context-related factors. This implies the need for monitoring level of maternal health services utilization in different settings in relation to locally influential factors. Therefore, this study has assessed the status of maternal health service utilization and factors affecting their health-services utilization.

\section{Methods}

\section{Study setting and design}

The study was conducted in selected districts of Jimma Zone, which is located $352 \mathrm{kms}$ from the capital Addis Ababa in southwest of Ethiopia. According to projection of 2007 population census, the zone has an estimated population of 3,261,371 (49.9\% women) in the year 2017 . From the total females, $23.1 \%$ were women in the child bearing age (WCBA), which imply a total of 753,377 WCBA residing in the zone. The zone consists of 20 rural districts and one special town administration (Agaro Town), 46 small urban and 512 rural kebeles (smallest formal administrative units). This study was conducted from 06 to 18 September 2017 as part of maternal and neonatal intervention baseline assessment of the rural districts. This was supplemented by key informant interviews of heads/experts of the district health offices and health centers.

\section{Study population/data source}

The study population for the questionnaire-based surveys of this study was WCBA who gave birth within one year preceding the survey. The heads/experts of district health offices and heads/experts of the heath institutions that have been at the position at least for six months during the survey were included into the key informant interviews. 


\section{Sample size determination and sampling procedure}

The data analyzed for this study are from a baseline study of maternal and newborn interventions, which has a control arm for the purpose of comparison after the intervention. Therefore, the sample size was determined using two-population proportion formula; considering $95 \%$ confidence interval, power of $80 \%$ to detect at least $10 \%$ difference between the two groups after the intervention. Based on previous community based study [7], the total sample size was estimated based on the study objective, using the variable which gives the largest sample size (\#758) among the indicators of service utilization of WCBA. Assuming 5\% non-response rate, the final sample size was estimated to be 796 respondents.

Initially six districts (30\% of the 20 districts) were selected purposely considering absence of other maternal and newborn intervention projects and their representativeness in terms of agroecological climate and physical accessibility to health services. Simple random sampling technique was employed to recruit the interviewed WCBA for the community-based study. A fresh list of mothers who gave births during a year preceding the study was obtained from health extension workers and used as sampling frames. The sample size was allocated to each selected kebele proportionally to the size of WCBA who fulfilled the inclusion criteria. Finally, selection of the study subjects was made randomly and independently based on the prepared list within each kebele until the required sample size was achieved (Fig. 1).

Furthermore, in-depth interviews of $30 \%$ of heads/experts of public health institutions and all district health offices of the districts were done. Accordingly, key informant interviews of 11 experts from public health institutions and six heads/experts of district health offices of the study districts were carried out.

\section{Data collection procedure}

The WCBA data was collected by interviewer-administered questionnaire (Additional file 2) whereas interview guide (Additional file 1) was used for the in-depth interviews. Twelve (two per district) data collectors who hold bachelor degree in health science fields and who are trained for two days collected the survey data. Similarly, six master degree holders in health discipline supervised the quantitative data collection and conducted the qualitative study using guidelines prepared for these purposes. The data

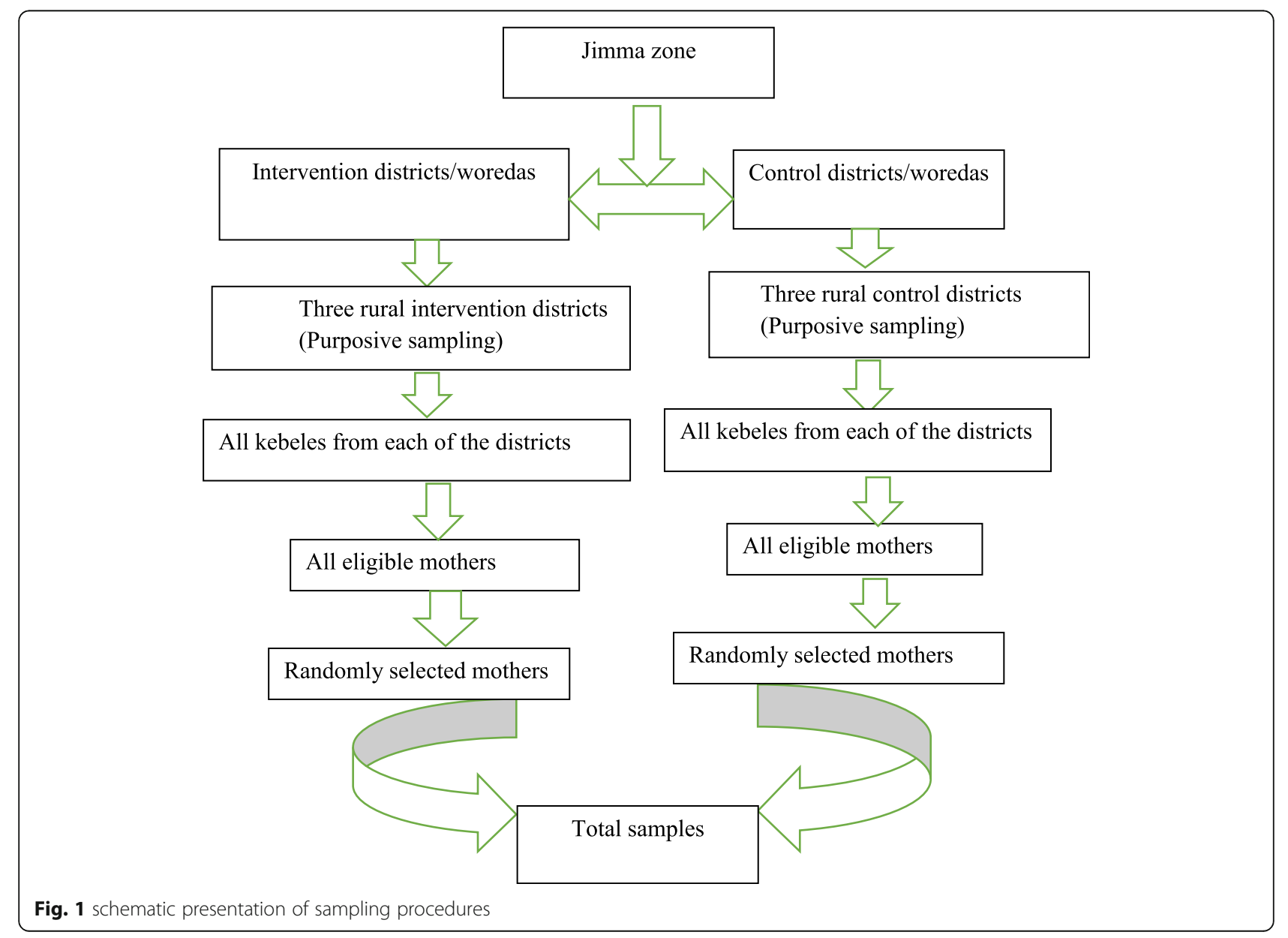


collection tools for the survey were pretested on $5 \%$ of the sample size outside the study setting before the commencement of the actual work. Sufficient training was given to data collectors and supervisors. In addition, the day-to-day activities of the data collection were closely supervised by the investigators. Data entry template was designed in EpiData version 3.1 to control error entries.

\section{Study variables}

Dependent/outcome variables

- Maternal and newborn healthcare utilization: ANC, Institutional delivery and PNC services

- Antenatal care (ANC) is the care provided by skilled health-care professionals to pregnant women in order to ensure the best health conditions for both the mother and the baby during pregnancy [33].

- Institutional delivery Institutional delivery means giving birth to a child in a medical institution under the overall supervision of trained and competent health personnel where there are more amenities available to handle the situation and save the life of the mother and child [34].

- Postnatal care (PNC) includes services provided to women and newborns immediately after delivery and up to six weeks thereafter, with the aim of ensuring optimum health for both the mothers and their infants [35]. In this study first PNC visit has been considered, which is consistent to EDHS 2016 [9].

\section{Independent variables/predictors}

- Demographic characteristics: age, parity, gravidity, marital status, ethnicity

- Socioeconomic characteristics: household economic status, availability and watching/listening of $\mathrm{TV}$ and radio; religion, educational status, occupational status, distance to health facilities

- Others: Respects given by health professionals, waiting time of clients, knowledge of pregnancy related danger signs

Data processing and analysis Data were checked, cleaned, and entered into EpiData version 3.1. Afterwards, data were exported and analyzed using SPSS $^{\circ}$ (IBM SPSS Statistics for Macintosh, Version 21.0. Armonk, NY). Both descriptive statistics and multivariable analytical model were used to summarize the data and identify association of independent variables with outcomes of the study, respectively. Based on a previous study definition [36], respondents who could correctly identify at least three key danger signs related to pregnancy, labor and delivery were considered to be knowledgeable of the key danger signs, or otherwise not. Adjusted odds ratios (AORs) with their corresponding 95\% CIs were used to assess the strength of the associations at $p$-value $\leq 0.05$ cut-off point for statistical significance. Additionally, qualitative data was transcribed and analyzed thematically.

\section{Results}

A total of 789 (99.1\% response rate) women in the childbearing age (WCBA) were included in the survey. The minimum and maximum ages of the study participants were 16 and 48 years, respectively. Close to half (47.9\%) of them were in the age range 25 to 34 years, and the majority of them were Muslims (89.7\%), Oromo ethnic group (87.2\%), married (95.6\%), housewives/ farmers (92.5\%) and had not attended formal education (88.5\%). Nearly half $(49.7 \%)$ of them had a radio and most of those who had the radio (88.5\%) reported that they listen to it regularly (Table 1 ).

Regarding the reproductive history of the study participants, almost half (49.7\%) of them got married below the age of 18 years whereas close to another half (48.8\%) of them got married between the age of 18 to 24 years. Again, a considerable proportion (45.4\%) of the mothers

Table 1 Socio-demographic characteristics of the respondents (WCBA), Jimma Zone, Oromia Regional State, Southwest Ethiopia September $2017(n=789)$

\begin{tabular}{|c|c|c|}
\hline Characteristics & Categories & Number (\%) \\
\hline \multirow[t]{4}{*}{ Age during the survey } & $\leq 18$ & $33(4.2)$ \\
\hline & $19-24$ & $255(32.3)$ \\
\hline & $25-34$ & $378(47.9)$ \\
\hline & $35-49$ & $123(15.6)$ \\
\hline \multirow[t]{2}{*}{ Religion } & Muslim & $708(89.7)$ \\
\hline & Christian* & $81(10.3)$ \\
\hline \multirow[t]{4}{*}{ Ethnicity } & Oromo & $688(87.2)$ \\
\hline & Amhara & $37(4.7)$ \\
\hline & Gurage & $19(2.4)$ \\
\hline & Others & $45(5.7)$ \\
\hline \multirow[t]{2}{*}{ Marital Status } & Married & 754 (95.6) \\
\hline & Not in marriage ${ }^{* *}$ & $35(4.4)$ \\
\hline \multirow[t]{3}{*}{ Educational status } & Unable to read \& write & $393(49.8)$ \\
\hline & Only read and write & $305(38.7)$ \\
\hline & Have formal education & $91(11.5)$ \\
\hline \multirow[t]{2}{*}{ Do you have radio } & Yes & $392(49.7)$ \\
\hline & No & $397(50.3)$ \\
\hline \multirow{2}{*}{$\begin{array}{l}\text { Radio listening (those } \\
\text { who have radio) }\end{array}$} & Yes & $347(88.5)$ \\
\hline & No & 45 (11.5) \\
\hline
\end{tabular}

*Christian: Orthodox $=8.4 \% ;$ Protestant $=1.5 \%$ \& Catholic $=0.4 \%$

${ }^{*}$ Not in marriage: Separated $=2.3 \%$; divorced $=1.4 \%$; widowed $=0.5 \%$ $\&$ single $=0.2 \%$ 
got pregnant at or below the age of 18 years. More than half $(58.2 \%)$ of them had two to five pregnancies and gave birth twice $(52.9 \%)$ or more $(5.7 \%)$; whereas $19.4 \%$ of the mothers reported having got more than five pregnancies. On the other hand, nearly one in ten $(9.3 \%)$ of the mothers reported having experienced abortions and stillbirths (1.6\%). Moreover, a quarter (25.3\%) of them reported to have encountered health problems during their recent pregnancies (Table 2).

Most (93.3\%) of the study participants reported having attended antenatal care (ANC) during their last pregnancy, mainly $(71.0 \%)$ starting at the second trimester. However, only $47.5 \%$ of them had attended the recommended $\mathrm{ANC}_{4+}$ visits per pregnancy. Majority (79.7\%) of them made the ANC visits at health centers followed by health posts $(15.0 \%)$; hence, a large proportion (83.4\%) of the mothers reported to have been attended by skilled health professionals. A large proportion $(72.9 \%)$ of the respondents reported to have received health information during the ANC visits though only half $(50.8 \%)$ of them remembered to have been informed about danger signs of pregnancy. Majority (86.7\%) of them reported to have been informed where to deliver; hence, more than three quarters (77.4\%) of them gave birth at health institutions, which signify the importance of health information for pregnant mothers to strengthen maternal and newborn health services (Table 3).

Table 2 Reproductive history of the respondents (WCBA), Jimma Zone, Oromia Regional State, Southwest Ethiopia, September $2017(n=789)$

\begin{tabular}{lll}
\hline Variables & Categories & Number (\%) \\
\hline Age at first marriage & $<18$ years & $392(49.7)$ \\
& $\geq 18$ years & $397(50.3)$ \\
Age at first pregnancy & $\leq 18$ years & $358(45.4)$ \\
& $\geq 19$ years & $431(54.6)$ \\
Number of life time pregnancies & 1 & $177(22.4)$ \\
& $2-5$ & $459(58.2)$ \\
Number of deliveries in the last 5 years & 1 & $153(19.4)$ \\
& 2 & $327(41.4)$ \\
Abortion experienced & $>2$ & $417(52.9)$ \\
& Yes & $73(5.7)$ \\
Number of abortions ever occurred & 1 time & $716(90.3)$ \\
Number of still births ever occurred & $\geq 2$ times & $13(1.6)$ \\
Health related problems & 1 & $9(1.1)$ \\
encountered during last pregnancy & $\geq 2$ & $4(0.5)$ \\
\hline
\end{tabular}

Table 3 Maternal health service utilization of the respondents (WCBA), Jimma Zone, Oromia Regional State, Southwest Ethiopia, September 2017 ( $n=789$ )

\begin{tabular}{|c|c|c|}
\hline Variables & Categories & Number $(\%$ \\
\hline \multirow[t]{2}{*}{ ANC visit } & Yes & $736(93.3)$ \\
\hline & No & $53(6.7)$ \\
\hline \multirow[t]{4}{*}{ Number of ANC visit } & 1 & $9(1.1)$ \\
\hline & 2 & $74(9.4)$ \\
\hline & 3 & $278(35.2)$ \\
\hline & $\geq 4$ & $375(47.5)$ \\
\hline \multirow[t]{4}{*}{ Time of first visit } & First trimester & $149(18.9)$ \\
\hline & Second trimester & $560(71.0)$ \\
\hline & Third trimester & $25(3.2)$ \\
\hline & I don't remember & $2(0.3)$ \\
\hline \multirow[t]{4}{*}{ Place of ANC visit } & Health Centre & $629(79.7)$ \\
\hline & Health post & $118(15.0)$ \\
\hline & Hospital & $33(4.2)$ \\
\hline & Private Clinic & $6(0.8)$ \\
\hline \multirow[t]{2}{*}{ ANC attendants } & Health professional & $618(84.0)$ \\
\hline & Health extension worker & $118(16.0)$ \\
\hline \multirow{2}{*}{$\begin{array}{l}\text { Information received } \\
\text { during ANC }\end{array}$} & Yes & $684(86.7)$ \\
\hline & No & $52(6.6)$ \\
\hline \multirow{3}{*}{$\begin{array}{l}\text { Given HE during } \\
\text { ANC visits }\end{array}$} & Yes & 575 (72.9) \\
\hline & No & $145(18.4)$ \\
\hline & I don't remember & $16(2.0)$ \\
\hline \multirow{3}{*}{$\begin{array}{l}\text { Informed about danger } \\
\text { signs of pregnancy }\end{array}$} & Yes & $401(50.8)$ \\
\hline & No & $166(21.0)$ \\
\hline & I don't remember & $8(1.0)$ \\
\hline \multirow[t]{2}{*}{ Informed where to deliver } & Yes & $684(86.7)$ \\
\hline & No & $52(6.6)$ \\
\hline \multirow[t]{2}{*}{ Place of delivery } & Home & $178(22.6)$ \\
\hline & Health Facility & $611(77.4)$ \\
\hline
\end{tabular}

Regarding postnatal care services, $92.0 \%$ of the mothers reported getting checkup while they were in the health institutions, half (50.3\%) of them within a day of their delivery, a third (33.8\%) of them at least six hours later after the delivery, yet the first checkups took place within six hours of delivery for three-fourth $(76.4 \%)$ of them. The present study shows that about a third (32.5\%) of those who gave birth at home had got checkups, but the rest did not get any professional support. The most noted postnatal services mentioned were advice on breastfeeding (56.1\%) and family planning (40.1\%), physical examination (34.6\%) and provision of family planning services (22.3\%).

Pertaining to the mothers' knowledge of danger signs, the respondents knew some danger signs related to pregnancy (60.8\%), labor \& delivery (59.3\%), and danger 
signs that can be manifested within first week after delivery $(51.3 \%)$. The major cited danger signs related to pregnancy were vaginal bleeding $(30.0 \%)$, severe headache $(29.3 \%)$ and persistent vomiting (28.0). Similarly, danger signs associated with labor \& delivery were mentioned to be vaginal bleeding (35.0\%), prolonged labor $(32.6 \%)$ and retained placenta $(20.9 \%)$. Again, the main danger signs that can occur within one week after delivery were mentioned to be severe vaginal bleeding (38.5\%) and high-grade fever (21.7\%).

A total of $116(14.7 \%)$ of the respondents reported that they have encountered health problems related to childbirth during their last deliveries. High-grade fever (32.8\%), excessive vaginal bleeding (31.9\%), and pain during urination $(12.1 \%)$ were the common problems listed by the respondents. Nearly three-fourth (73.7\%) of them sought treatment in the nearby health facility for their health problems. Regarding the attitude of husbands towards institutional delivery, $94.6 \%$ of the study participants said that their husbands were supportive and have a favorable attitude towards institutional delivery (Table 4).

Regarding delivery services, 599 (77.9\%) study participants reported having received delivery services at the health facilities whereas the remaining $22.1 \%$ of the mothers delivered at home. The reported reasons for home delivery were perceived short labor duration (74.2\%), long distance to health facilities (12.9\%) and absence of delivery service $(9.5 \%)$ in the nearby health facilities (health posts). Among those mothers who delivered at the health facilities, $58(9.7 \%)$ reported to have paid for the services and out of whom the payment was costly for seven (12.1\%) of them. Concerning distance to the health institutions where they received health care, majority (93.5\%) of the interviewed mothers reported walking less than one hour to reach the nearest health facility. Close to a quarter $(24.8 \%)$ of the respondents reported that they waited for long time to receive the services.

On the other hand, majority of the mothers responded that their privacies were maintained during intrapartum procedures $(87.1 \%)$ and the health professionals were respectful to them $(88.1 \%)$. The overall satisfaction level of the mothers with different components of the maternal health services was categorized to be very good (46.2\%), good (37.2\%), fair (10.3\%) and poor $(5.6 \%)$ or very poor (0.8\%) (Table 5).

\section{Factors affecting utilization of maternal healthcare services}

The satisfaction levels (differences) did not show significant association with related independent variables. Husband educational status, age of mothers during the survey and at first marriage, distance to health facility and hearing information from TV did not show significant association with ANC utilization of the mothers.
On the other hand, age at first pregnancy, family size, decision-making pattern about ANC and getting information on the advantages of ANC showed at least marginally significant associations at multiple regression level analyses. There is significant association between age at first pregnancy and ANC attendance, where mothers who got their first pregnancy at the age of 19 years or above were (AOR: 2.6; 95\% CI: 1.0, 6.5; $P=$ $0.05)$ more likely to attend ANC compared to mothers who got pregnant before the age of 19 years.

Mothers who had 4 to 6 family members were more than two times (AOR: 2.3, 95\% IC: 1.1, 4.9) more likely to make ANC follow-up compared to those mothers with more than six family members. Mothers who make decision with their husbands (AOR: 30.9; 955 CI: 8.3, 115.4) or whose husbands make decision (AOR: 15.3; 95\%CI: 3.8, 62.3) on ANC attendance were more likely to make ANC follow-up compared to those mothers who make the decision themselves on ANC follow up. Mothers who get information on ANC benefits from radio were more than two times (AOR: 2.5 ; 95\% CI: 1.1 , 5.6) more likely to make ANC follow up compared to those mothers who did not listen to the radio (Table 6).

Factors like maternal education, age of mothers (at first marriage, at first pregnancy and during the survey), distance to nearest health facilities, hearing information from radio about institutional delivery, decision-making pattern to seek institutional delivery, and owned land size did not show significant association with utilization of institutional delivery at multiple logistic regression levels.

On the other hand, husbands' education, number of pregnancies, family size, hearing information from TV on the befits of institutional delivery and attitudes of husbands towards institutional delivery showed significant associations (at varying degree) with attendance of institutional delivery. Mothers whose husbands can read/write (AOR: 1.6; 95\% CI: 1.1, 2.5) and who have formal education (AOR: 2.8; 95\% CI: 1.1, 6.8) were more likely to give birth at health institutions. Mothers with family sizes 1 to 3 (AOR: 3.0; 95\% CI: 1.2, 7.6) and 4 to 6 (AOR: 2.3 ; 95\% CI: 1.2, 4.1) were more likely to give birth at health institutions compared to mothers whose family size is greater than six. Mothers who get information from TV on benefits were more than two times (AOR: $2.1 ; 95 \%$ CI: $1.0,4.4 ; P=0.04$ ) more likely to make ANC follow-up compared to those mothers who did not get information from TV. Finally, mothers whose husbands have a positive attitude towards institutional delivery were ten times (AOR: 10.2; 95\%CI: 4.0, 25.9) more likely to give birth at health institutions (Table 7).

Most (92.0) of the mothers who gave birth in a health facility, reported having had PNC checkups, mainly (78.9\%) within six hours of delivery. However, only close to a third (32.5\%) of those mothers who delivered at home 
Table 4 Mothers' knowledge of danger signs related to pregnancy and problems encountered after delivery, Jimma Zone, Oromia Regional State, Southwest Ethiopia, September $2017(n=789)$

\begin{tabular}{|c|c|c|c|c|c|}
\hline Variables & Categories & $\begin{array}{l}\text { Number } \\
(\%)\end{array}$ & Variables & ories & $\begin{array}{l}\text { Number } \\
(\%)\end{array}$ \\
\hline \multirow{9}{*}{$\begin{array}{l}\text { Knew danger signs related } \\
\text { to pregnancy }(51.1 \%)\end{array}$} & Vaginal bleeding & $291(36.9)$ & Not a & t all & $12(10.5)$ \\
\hline & Severe headache & $190(24.1)$ & \multirow{3}{*}{$\begin{array}{l}\text { Husband's attitudes towards } \\
\text { institutional delivery }\end{array}$} & ortive & $746(94.6)$ \\
\hline & Blurred vision & $90(11.4)$ & & upportive & $22(2.8)$ \\
\hline & Persistent vomiting & $72(9.1)$ & & know & $21(2.7)$ \\
\hline & Swollen hands/face & $67(8.5)$ & & & \\
\hline & Hypertension & $41(5.2)$ & \multirow{9}{*}{\multicolumn{3}{|c|}{$\begin{array}{l}\text { reported having PNC checkups. According to the findings } \\
\text { from key informant interviews, the main maternal and } \\
\text { newborn health problems were unsafe delivery settings, } \\
\text { which lead to hypothermia, birth asphyxia, neonatal } \\
\text { sepsis, and febrile illness. Infectious diseases such as } \\
\text { pneumonia, diarrhea, measles, and undernutrition were } \\
\text { mentioned to be the major killers of infants. Poor } \\
\text { health-seeking behavior, including home delivery and } \\
\text { Table } 5 \text { Health facility related factors among women who } \\
\text { delivered their last child in health institution, Jimma Zone, } \\
\text { Oromia Regional State, Southwest Ethiopia, September } 2017\end{array}$}} \\
\hline & $\begin{array}{l}\text { Foul smelling } \\
\text { vaginal discharge }\end{array}$ & $29(3.7)$ & & & \\
\hline & Other & $30(7.5)$ & & & \\
\hline & $\begin{array}{l}\text { Knew } \geq 3 \text { of the } \\
\text { danger signs }\end{array}$ & $111(14.1)$ & & & \\
\hline \multirow{7}{*}{$\begin{array}{l}\text { Knew danger signs related } \\
\text { to labor and delivery (59.3\%) }\end{array}$} & Vaginal bleeding & $276(35.0)$ & & & \\
\hline & Prolonged labor (> 12 h) & $257(32.6)$ & & & \\
\hline & Retained placenta & $165(20.9)$ & & & \\
\hline & Hypertension & $55(7.0)$ & & & \\
\hline & Others & $52(6.6)$ & & & \\
\hline & Knew $\geq 3$ of the & $59(7.5)$ & $\underline{\text { Variables }}$ & Categories & $N(\%)$ \\
\hline & danger signs & & Received delivery service & yes & $611(77.4)$ \\
\hline \multirow{10}{*}{$\begin{array}{l}\text { Knew danger signs that occur } \\
\text { within the first week after birth, } \\
\text { \# } 405 \text { (51.3\%) }\end{array}$} & $\begin{array}{l}\text { Severe vaginal } \\
\text { bleeding }\end{array}$ & $304(38.5)$ & & No & $178(22.6)$ \\
\hline & High fever & $171(21.7)$ & \multirow[t]{2}{*}{ Payment for the delivery services } & Yes & $58(9.7 \%)$ \\
\hline & Fit & $60(7.6)$ & & No & $540(90.3 \%$ \\
\hline & Hypertension & $45(5.7)$ & \multirow[t]{4}{*}{ Payment for the services } & Too expensive & $7(12.1)$ \\
\hline & Swollen hands/face & $20(2.5)$ & & Fair & $39(67.2)$ \\
\hline & Offensive vaginal & $51(6.5)$ & & Cheap & $8(13.8)$ \\
\hline & discharge & & & I don't remember & $4(6.9)$ \\
\hline & Other & $60(7.6)$ & \multirow[t]{2}{*}{ Time to reach health facility } & $<1 \mathrm{~h}$ & $719(93.5)$ \\
\hline & Knew $\geq 3$ of the & $71(9.0)$ & & $1-2 h$ & $50(6.5)$ \\
\hline & danger signs & & \multirow[t]{2}{*}{ Waiting time to get delivery service } & Long & $146(24.8)$ \\
\hline $\begin{array}{l}\text { Health problem encountered } \\
\text { after delivery }\end{array}$ & yes & $116(14.7)$ & & Short & $443(75.2)$ \\
\hline & no & $673(85.3)$ & \multirow[t]{2}{*}{ Health workers have confidence } & Yes & $542(92.5)$ \\
\hline Sever vaginal bleeding & yes & $37(31.9)$ & & No & $44(7.5)$ \\
\hline & no & $79(68.1)$ & \multirow[t]{3}{*}{ Privacy during the procedures } & yes & $513(87.1)$ \\
\hline High grade fever & yes & $38(32.8)$ & & no & $40(6.8)$ \\
\hline & no & $78(67.2)$ & & I don't know & $36(6.1)$ \\
\hline Painful urination & yes & $14(12.1)$ & \multirow[t]{2}{*}{ Health workers were respectful } & yes & $519(88.1)$ \\
\hline & no & $102(87.9)$ & & no & $60(10.2)$ \\
\hline \multirow[t]{2}{*}{ Offensive vaginal discharge } & yes & $4(3.4)$ & & I don't know & $10(1.7)$ \\
\hline & no & $112(96.6)$ & \multirow[t]{2}{*}{ Overall satisfaction level by the services } & Very good & $282(46.2)$ \\
\hline Do not remember & & $7(6.7)$ & & Good & $227(37.2)$ \\
\hline \multirow{3}{*}{$\begin{array}{l}\text { Support sought for the } \\
\text { health problems encountered }\end{array}$} & Yes, at health facility & $84(73.7)$ & & Fair & $63(10.3)$ \\
\hline & Yes, at home & $18(15.8)$ & & Poor & $34(5.6)$ \\
\hline & & & & Very Poor & $5(0.8)$ \\
\hline
\end{tabular}

Table 4 Mothers' knowledge of danger signs related to pregnancy and problems encountered after delivery, Jimma Zone, Oromia Regional State, Southwest Ethiopia, September 2017 ( $n=789)$ (Continued)

reported having PNC checkups. According to the findings from key informant interviews, the main maternal and newborn health problems were unsafe delivery settings, which lead to hypothermia, birth asphyxia, neonatal sepsis, and febrile illness. Infectious diseases such as pneumonia, diarrhea, measles, and undernutrition were mentioned to be the major killers of infants. Poor

Table 5 Health facility related factors among women who ma Zone, Regional State, Southwest Ethiopia, September 2017 
Table 6 Factors affecting ANC Utilization among women in the child bearing age group, Jimma Zone, Oromia Regional State, Southwest Ethiopia, 2017

\begin{tabular}{|c|c|c|c|c|c|c|}
\hline \multirow[t]{2}{*}{ Variables } & \multirow[t]{2}{*}{ Categories } & \multicolumn{2}{|c|}{ ANC use } & \multicolumn{2}{|c|}{ Odds Ratio (95\% Cl) } & \multirow{2}{*}{$\begin{array}{l}P \text { Values } \\
\text { (Adjusted) }\end{array}$} \\
\hline & & Yes & No & Crude & Adjusted & \\
\hline \multirow[t]{3}{*}{ Husband Education } & Does not read/write & 276 & 26 & 1 & 1 & \\
\hline & Read and write & 327 & 18 & $1.7(0.9,3.2)$ & $1.2(0.6,2.6)$ & 0.56 \\
\hline & Formal educ. & 104 & 3 & $3.3(1.0,11.0)$ & $1.1(0.3,4.3)$ & 0.86 \\
\hline \multirow[t]{4}{*}{ Age of mothers during the survey } & $\leq 18$ & 29 & 4 & $1.1(0.3,3.5)$ & $2.5(0.3,21)$ & 0.40 \\
\hline & $19-24$ & 244 & 11 & $3.3(1.5,7.4)$ & $1.6(0.5,4.8)$ & 0.41 \\
\hline & $25-34$ & 356 & 22 & $2.4(1.2,4.8)$ & $1.8(0.8,4.0)$ & 0.18 \\
\hline & $35-49$ & 107 & 16 & 1 & 1 & \\
\hline \multirow[t]{2}{*}{ Age at first marriage } & $<18$ & 328 & 32 & 1 & 1 & \\
\hline & $\geq 18$ & 375 & 21 & $1.5(0.9,2.7)$ & $0.6(0.3,1.7)$ & 0.36 \\
\hline \multirow[t]{2}{*}{ Age at first pregnancy } & $\leq 18$ & 328 & 32 & 1 & 1 & \\
\hline & $\geq 19$ & 408 & 21 & $1.9(1.1,3.5)$ & $2.6(1.0,6.5)$ & 0.05 \\
\hline \multirow[t]{3}{*}{ Distance to health facility } & $<30$ Minutes & 302 & 12 & $2.2(0.7,7.1)$ & $1.5(0.4,5.4)$ & 0.58 \\
\hline & 30-60 Minutes & 375 & 30 & $1.1(0.4,3.2)$ & $1.1(0.3,3.8)$ & 0.88 \\
\hline & $>60$ Minutes & 46 & 4 & 1 & 1 & \\
\hline \multirow[t]{3}{*}{ Family size } & $1-3$ & 135 & 4 & $4.5(1.6,13.1)$ & $3.3(0.8,14.1)$ & 0.11 \\
\hline & $4-6$ & 384 & 20 & $2.6(1.4,4.6)$ & $2.3(1.1,4.9)$ & 0.04 \\
\hline & $\geq 7$ & 217 & 29 & 1 & 1 & \\
\hline \multirow[t]{3}{*}{ Decision maker to seek ANC } & Husband \& wife & 579 & 31 & $4.7(1.9,11.5)$ & $30.9(8.3,115.4)$ & 0.00 \\
\hline & Husband only & 129 & 15 & $2.2(0.8,5.8)$ & $15.3(3.8,62.3)$ & 0.00 \\
\hline & Wife herself & 28 & 7 & 1 & 1 & \\
\hline \multirow[t]{2}{*}{ Information from radio } & Yes & 316 & 11 & $2.9(1.5,5.7)$ & $2.5(1.1,5.6)$ & 0.03 \\
\hline & No & 420 & 42 & 1 & 1 & \\
\hline \multirow[t]{2}{*}{ Information from TV } & Yes & 130 & 2 & $5.5(1.3,22.8)$ & - & 0.99 \\
\hline & No & 606 & 51 & 1 & 1 & \\
\hline
\end{tabular}

delayed arrival of the clients to health facilities, were mentioned to have exposed mothers to excessive bleeding and other complications, including fistula in some instances.

The key informants explained that the major challenges in implementation of maternal and newborn health services in their respective districts were found to be low number of trained personnel/training opportunity; lack of transportation, including poor infrastructure and long distance to reach health facilities; delayed health seeking, husband's influences on some of the services such as low utilization of long-acting contraceptives; low performance of health developmental armies at community level; lack/interruption of power supply and lack of functional refrigerators. Shortage of drugs and supplies were also cited to be major limitations from the service providers' side.

The key informants also discussed the prevailing common practices of maternal and newborn health services. They mentioned that maternal waiting areas have been arranged at respective health centers. The community uses traditional 'stretcher' called 'Siree' to carry mothers to accessible places where they get ambulances to reach health facilities. Local women contribute money (One Ethiopian Birr for one mother) \& different raw items used to prepare food as part of the birth preparedness of pregnant mothers. HEWs perform most of the PNC activities such as counseling \& vaccinations at their respective catchment areas. One mentioned harmful traditional practice was an early marriage where girls can be married at age as low as 14 years.

\section{Discussion}

Health check-ups during pregnancy, institutional delivery, and postnatal care are considered to be the most effective health interventions for preventing maternal and newborn morbidity and mortality, particularly in places where the general health status of the women is poor [37-39]. This study tried to assess the status of maternal health care service utilization and factors influencing utilization of the services among mothers who gave birth 
Table 7 Factors affecting place of institutional delivery among mothers, Jimma Zone, Oromia Regional State, Southwest Ethiopia, September, 2017

\begin{tabular}{|c|c|c|c|c|c|c|}
\hline \multirow[t]{2}{*}{ Variables } & \multirow[t]{2}{*}{ Categories } & \multicolumn{2}{|c|}{ Place of delivery } & \multicolumn{2}{|c|}{ Odds Ratios (95\% Cl) } & \multirow{2}{*}{$\begin{array}{l}P \text { Values } \\
\text { (Adjusted }\end{array}$} \\
\hline & & $\mathrm{HF}$ & Home & Crude & Adjusted & \\
\hline \multirow[t]{3}{*}{ Mother Education } & Illiterate & 276 & 117 & 1 & 1 & \\
\hline & Read \&write & 251 & 54 & $2.0(1.4,2.9)$ & $1.2(0.7,1.9)$ & 0.517 \\
\hline & Formal educ. & 84 & 7 & $5.1(2.3,11.3)$ & $2.3(0.8,6.8)$ & 0.127 \\
\hline \multirow[t]{3}{*}{ Husband Education } & Illiterate & 202 & 100 & 1 & 1 & \\
\hline & Read \& write & 281 & 64 & $2.2(1.5,3.1)$ & $1.6(1.1,2.5)$ & 0.020 \\
\hline & Formal educ. & 98 & 9 & $5.4(2.6,11.1)$ & $2.8(1.1,6.8)$ & 0.025 \\
\hline \multirow[t]{4}{*}{ Age of mothers during survey } & $\leq 18$ & 31 & 2 & $6.7(1.5,29.3)$ & $8.3(1.4,51)$ & 0.024 \\
\hline & $19-24$ & 210 & 45 & $2.0(1.2,3.3)$ & $1.4(0.6,2.9)$ & 0.022 \\
\hline & $25-34$ & 284 & 94 & $1.3(0.8,2.0)$ & $1.1(0.7,2.1)$ & 0.429 \\
\hline & $35-49$ & 86 & 37 & 1 & 1 & \\
\hline \multirow[t]{3}{*}{ Number of pregnancy (Gravidity) } & 1 & 154 & 23 & $2.7(1.6,4.5)$ & $0.4(0.1,1.2)$ & 0.090 \\
\hline & $2-4$ & 283 & 86 & $1.3(0.9,1.9)$ & $0.4(02,0.7)$ & 0.006 \\
\hline & $\geq 5$ & 174 & 69 & 1 & 1 & \\
\hline \multirow[t]{2}{*}{ Age at first pregnancy } & $\leq 18$ & 259 & 101 & 1 & 1 & \\
\hline & $\geq 19$ & 352 & 77 & $1.8(1.3,2.5)$ & $1.8(0.9,3.1)$ & 0.057 \\
\hline \multirow[t]{3}{*}{ Distance to health institutions } & $<30$ Minutes & 276 & 38 & $2.8(1.4,5.7)$ & $2.2(1.0,4.8)$ & 0.054 \\
\hline & 30-60 Minutes & 289 & 116 & $1.0(0.5,1.9)$ & $1.0(0.5,2)$ & 0.929 \\
\hline & $>60$ Minutes & 36 & 14 & 1 & 1 & \\
\hline \multirow[t]{3}{*}{ Family size } & $1-3$ & 124 & 15 & $4.1(2.2,7.4)$ & $3.0(1.2,7.6)$ & 0.024 \\
\hline & $4-6$ & 322 & 82 & $1.9(1.3,2.8)$ & $2.3(1.2,4.1)$ & 0.008 \\
\hline & $\geq 7$ & 165 & 81 & 1 & 1 & \\
\hline \multirow[t]{3}{*}{ Decision maker } & Husband \& wife & 483 & 127 & $1.5(0.7,3.3)$ & $1.3(0.4,4.7)$ & 0.680 \\
\hline & Husband only & 103 & 41 & $1.0(0.4,2.3)$ & $1.0(0.3,3.4)$ & 0.978 \\
\hline & Wife herself & 25 & 10 & 1 & 1 & \\
\hline \multirow[t]{2}{*}{ Information from radio } & Yes & 260 & 67 & $1.2(0.9,1.7)$ & $0.8(0.5,1.2)$ & 0.325 \\
\hline & No & 351 & 111 & 1 & 1 & \\
\hline \multirow[t]{2}{*}{ Information from TV } & Yes & 120 & 12 & $3.4(1.8,6.3)$ & $2.1(1.0,4.4)$ & 0.040 \\
\hline & No & 491 & 166 & 1 & 1 & \\
\hline \multirow[t]{2}{*}{ Age at first marriage } & $<18$ & 289 & 102 & 1 & 1 & \\
\hline & $\geq 18$ & 320 & 76 & $1.5(1.1,2.1)$ & $0.9(0.5,1.6)$ & 0.718 \\
\hline \multirow[t]{2}{*}{ Land size owned by $\mathrm{HH}$} & $\leq 1 \mathrm{ha}$ & 40 & 588 & 1 & 1 & \\
\hline & $>1$ ha & 13 & 148 & $0.5(0.4,0.8)$ & $0.7(0.4,1.0)$ & 0.063 \\
\hline \multirow[t]{2}{*}{ Husband attitude towards HF delivery } & Supportive & 36 & 710 & $5.4(2.910 .1)$ & $10.2(4.0,25.9)$ & 0.000 \\
\hline & Not supportive & 17 & 26 & 1 & 1 & \\
\hline \multirow[t]{2}{*}{ Number of parities within five years } & 1 & 274 & 53 & $1.9(1.3,2.6)$ & $1.4(0.8,2.3)$ & 0.236 \\
\hline & $\geq 2$ & 337 & 125 & 1 & 1 & \\
\hline
\end{tabular}

in the last one year prior to the survey, in six districts of Jimma Zone Oromia Regional State, Southwest Ethiopia. The study also tried to see the knowledge and attitude of mothers on ANC, delivery and PNC services.

This study shows that $93.3 \%$ of women visited health facilities at least once during their recent pregnancy for antenatal care. However, only $47.5 \%$ of them had attended the recommended four visits. This result is higher than studies conducted in other parts of the country: in Eastern Ethiopia, only $10 \%$ of women attended four ANC visits [40], in Dejen and Aneded districts, Northwest Ethiopia, only $12 \%$ of the women reported to have attended the 
recommended four ANC visits [41] and the 2016 EDHS report for Oromia Region shows only $50.7 \%$ of the mothers attended at least one ANC visit [9]. The high coverage of ANC service in the area might have been attributed to the current massive health promotion activities on maternal and child health issues by the government and other developmental nongovernmental organizations, which might have also increased awareness and health seeking behavior of the respondents and accessibility of the services.

With regard to the timing of the first ANC visit, this study shows that more than two-third (70\%) of women went to a health facility for ANC in the second trimester of their pregnancy whereas, less than one fifth (18.9\%) of them visited health facility during the first trimester. The finding is consistent with previous studies done in Northwest Ethiopia [42] and in Eastern Ethiopia [40]. However, it is less than a study conducted in Nigeria [43], where $28 \%$ of the pregnant mothers visited health facilities during the first trimester. There were marginally significant associations between age of the mothers at first pregnancy, family size, decision-making pattern on ANC visits as well as getting information from radio and ANC attendance of the mothers. In contrast, studies done in Eastern [40, 44] and Northwest Ethiopia [41] revealed that ANC utilization of mothers is affected by maternal socio-demographic factors such as educational status, marital status, urban-rural residence, distance to health facilities, plan of pregnancy, history of abortion and illnesses, and knowledge of pregnancy complications.

According to the present findings, a significant proportion $(95.6 \%)$ of the mothers reported that they were not vaccinated against tetanus during ANC visits. This contrasts other studies, which reported $77.6 \%$ [45] and 72.5\% [46] two or more tetanus vaccination $\left(\mathrm{TT}_{2}+\right)$ among the study participants. The possible reason behind this fact could be more mothers might have completed the vaccination prior to their recent ANC visits and the health professional might also have known this fact as the vaccination cards are usually kept at the health facilities.

1This study revealed that more than three-fourth (77.4\%) of the respondents reported having delivered their last child in health facilities. The main predictors of institutional delivery were husband's education and supportive attitude and small family size of the mothers. A similar finding was observed in a recent study done in southern Ethiopia, in which $78.3 \%$ of women delivered their last child in the health facility [47], where maternal age, education, religion, occupation, access to information, residence, knowledge of danger signs and ANC visits were mentioned to be predictors of institutional delivery. However, the finding was higher than studies done in different parts of the country and compared to the national EDHS 2016 report, where only $26 \%$ of the deliveries in Ethiopia and $18.8 \%$ in Oromia Region took place at health facilities.
Other studies done in Dodota [19] and Goba [46, 48] districts, both southeastern Ethiopia, reported similar findings that only 18.2 and $47 \%$ of the mothers delivered their last child in health institutions, respectively.

The possible explanations for the higher service utilization might be due to high commitment of the government, which requires most kebeles to be home delivery free owed to the expansion of the health extension programs and training of health development army, which improves the utilization of health services by linking community and health facilities, particularly health centers. According to a recent assessment conducted by Ethiopian Public Health Institute (EPHI) and partner institutions [49], almost all governmental health institutions offer normal delivery services.

The present study shows that $92.0 \%$ of the study participants have some postnatal care services. This result is higher than the findings of studies conducted in South Ethiopia [50], West Ethiopia [51], Rwanda [52] and Kenya [53], where those who got postpartum services constituted 51.4, 20.2, $47.9,12.8$, and $46.2 \%$, respectively. The major predictors of PNC were mentioned to be awareness of obstetric danger signs, mothers' autonomy of decision-making, four or more ANC visits, institutional delivery, secondary level education, better incomes, and employment status of the mothers. A systematic review based study [54] on PNC services in developing countries reported an average of $36.0 \%$ PNC utilization, where most of the aforementioned factors were also found to be significantly associated with the PNC attendance.

The present study shows that overall satisfaction of the mothers with the maternity services was judged to be very good (46.2\%) and good (37.2\%), implying $83.4 \%$ of the mothers were satisfied with the services provided to them. This is in contrast to the finding of a study conducted in Addis Ababa [25], where only 19.0\% of the mothers reported satisfaction with $\mathrm{MNCH}$ services. Such gap in satisfaction level might be due to perception difference as women in the towns are more educated and expected to judge the expected level of care and supports to be provided by health professionals. Studies conducted in Addis Ababa [26] and Accra [55] confirm this fact that higher level education, better income, and urban residence were the predictors of dissatisfaction; moreover, perceptions of clinical competency and emotional supports affect satisfaction status of mothers.

This study has some limitations. Obviously, social desirability bias might have affected responses of both the mothers and the key informants in favor of wanted behaviors. There is also the possibility of recall bias, thus the study participants might have not correctly addressed past events in this regard. As the study is cross-sectional, it may not reflect the whole picture of maternal health services utilization status and influencing factors, particularly seasonal dependent factors. 


\section{Conclusions}

Health care attendance of the mothers during pregnancy was fairly high; however, most of the mothers started ANC lately and had not completed the recommended number of ANC visits. Although, both institutional delivery and postnatal care services were high, there were still some mothers who delivered at home without the support of skilled attendants. Husband education, attitude of the husbands and family size of the mothers were factors significantly affecting institutional delivery. Poor health-seeking behavior, including home delivery and delayed arrival of the mothers, were mentioned to have exposed mothers to excessive bleeding and other complications. Shortage of medical supplies was also cited as rate limiting factor.

Therefore, maintaining/improving the witnessed high-level of newborn and maternal health services by increasing awareness and health seeking behavior of the community using well-designed and locally contextualized IEC/BCC strategy is important. Improving capacity of the health facilities, including the provision of standard in-service training to the health personnel, and fulfilling essential equipment and supplies to ensure optimum newborn and maternal health services can improve the maternal health service utilization. Reaching mothers who are still inaccessible due to distance and other barriers to benefit them from newborn and maternal health services by facilitating transportation optimizing outreach health services and increasing scope of health information communication need due attention.

\section{Additional files}

Additional file 1: Key informant interview guide: (PDF $411 \mathrm{~kb}$ )

Additional file 2: Survey questionnaire: WCBA_HHQ1_Base_End. The questionnaire has been developed and customized mainly from the Ethiopian Health and Demographic Survey (EDHS) report, maternal health section: https://dhsprogram.com/publications/publication-fr328-dhs-finalreports.cfm We have uploaded the PDF of the questionnaire as an additional file. (PDF $165 \mathrm{~kb}$ )

\begin{abstract}
Abbreviations
ANC: Antenatal care; AOR: Adjusted odds ratio; BCC: Behavioural change communication; CBNC: Community based neonatal care; EDHS: Ethiopian demographic and health survey; EPHI: Ethiopian public health institute; FMOH: Federal ministry of health; HEWs: Health extension workers; ICCM: Integrated community case management; IEC: Information, education and communication; IMNCl: Integrated management of neonatal and child illnesses; KOICA: Korea international cooperation agency; MDGs: Millennium development goals; MNCH: Maternal, neonatal and child health; PNC: Postnatal care; SDGS: Sustainable development goals; TT: Tetanus toxoid; WCBA: Women in the childbearing age; WHO: World health organization
\end{abstract}

\section{Acknowledgments}

The authors greatly acknowledge KOICA for funding the study. The authors are also grateful to all research assistants who were involved in data collection, supervisions and data encoding activities. The study participants are also thankfully acknowledged for providing valuable information.

\section{Funding}

Korean International Cooperation Agency (KOICA) covered the costs of this research. KOICA did not have role in the research design, data collection, analysis and interpretation, and writing of the manuscript.

\section{Availability of data and materials}

The datasets used and/or analyzed during the current study are available from the corresponding author on reasonable request.

\section{Authors' contributions}

EKG: Participated in design, data acquisition and analysis, and critically reviewing the manuscript. $\mathrm{KKH}$ : Involved in the administrative matters, acquisition of data and critically reviewed the manuscript. LSD: Involved in the inception, design, data acquisition, analysis and interpretation, and wrote the manuscript. MA: Involved in the inception, design, acquisition of data, analysis and reviewing the manuscript. MB: Participated in the inception to design, acquisition of data, analysis and reviewing the manuscript. MG: Participated in data acquisition, data management and analysis as well as reviewing the manuscript. TB: Participated in the inception, design, acquisition of data, analysis and reviewing the manuscript. YA: Involved in the design, acquisition of data, and critically reviewed the manuscript. All authors read and approved the final manuscript.

\section{Ethics approval and consent to participate}

Ethical clearances were obtained from the Ethical Review Committee of the Institute of Health of Jimma University and Oromia Regional Health Bureau as well as Jimma Zonal Health Office to conduct the baseline survey research on the WCBA and respective health facilities as part of the maternal and newborn health interventions. Relevant offices and health facilities were communicated by a formal letter of permission. In addition, written consent was obtained from every study participant before data collection and individual information is kept confidential. The Ethical Review Committee has also approved the concent procedure of all the WCBA. This is a baseline assessment for health intervention and the study would not adversely affect the study participants/institutions; rather, it is expected to improve the health and well beings of mothers and newborns.

Consent for publication

Not Applicable

\section{Competing interests}

The authors declare that they do not have competing interest.

\section{Publisher's Note}

Springer Nature remains neutral with regard to jurisdictional claims in published maps and institutional affiliations.

\section{Author details \\ ${ }^{1}$ Department of Epidemiology, Faculty of Public Health, Jimma University, Jimma, Ethiopia. ${ }^{2}$ Department of Pediatrics and Child Health, Jimma University Medical Center, Jimma, Ethiopia. ${ }^{3}$ Department of Obstetrics and Gynecology, Jimma University Medical Center, Jimma, Ethiopia. ${ }^{4}$ Department of Internal Medicine, Jimma University Medical Center, Jimma, Ethiopia. ${ }^{5} \mathrm{Jimma}$ Zone Health Office, Jimma, Ethiopia. ${ }^{6} \mathrm{KOICA}$ Ethiopia Center, Jimma, Ethiopia. ${ }^{7}$ Department of Population and Family Health, Faculty of Public Health, Jimma University, Jimma, Ethiopia.}

Received: 25 October 2018 Accepted: 7 May 2019

Published online: 22 May 2019

\section{References}

1. Lindtjørn B, Mitiku D, Zidda Z, Yaya Y. Reducing maternal deaths in Ethiopia: results of an intervention Programme in Southwest Ethiopia. PLoS One. 2017;12(1):e0169304 doi:0169310.0161371/journal.pone.0169304.

2. Pablos-Mendez A, Valdivieso V, Flynn-Saldaña K. Ending preventable child and maternal deaths in Latin American and Caribbean countries (LAC). Perinatol Reprod Hum. 2013;27(3):145-52. https://www.medigraphic.com/ pdfs/inper/ip-2013/ip133b.pdf.

3. Berhan Y, Berhan A. Review of maternal mortality in ethiopia: a story of the past 30 years. Ethiop J Health Sci. 2014(Special Issue:3-14. https://doi.org/10. 4314/ejhs.v4324i4311.4312S. 
4. Tessema GA, Laurence CO, Melaku YA, Misganaw A, Woldie SA, Hiruye A, Amare AT, Lakew Y, Zeleke BM, Deribew A. Trends and causes of maternal mortality in Ethiopia during 1990-2013: Findings from the Global Burden of Diseases study 2013. BMC Public Health. 2017;17:160. https://doi.org/10. 1186/s12889-12017-14071-12888.

5. Kassebaum N, Murray CJL, Barber R, Dandona L, Hay SI, Larson H, Lim S: Global, regional, and national levels of maternal mortality, 1990â€"2015: a systematic analysis for the Global Burden of Disease Study 2015. Lancet 2016, 388:1775-1812 ; doi.org/1710.1016/S0140-6736(1716)31470-31472.

6. Moreda T, Gebisa K. Assessment of postnatal care service utilization and associated factors among mothers attending Antinatal Care at Ambo Health Facilities. Epidemol Int J. 2018;2(2):000111.

7. Teferra AS, Alemu FM, Woldeyohannes SM. Institutional delivery service utilization and associated factors among mothers who gave birth in the last 12 months in Sekela District, north west of Ethiopia: a community - based cross sectional study. BMC Pregnancy and Childbirth. 2012;12:74. https:// www.ncbi.nlm.nih.gov/pmc/articles/PMC3449175/pdf/1471-2393-12-74.pdf

8. Hamdela B, Getnet Y, Abageda M. Predictors of health facility delivery service utilization in Lemo District, South Ethiopia: unmatched case control study. J Preg Child Health. 2015;2(2) https://doi.org/10.4172/2376-4127X. 1000152.

9. Central Statistical Agency C, [Ethiopia] and ICF: Ethiopia Demographic and Health Survey 2016. Addis Ababa: Ethiopia, and Rockville, Maryland, USA: CSA and ICF.

10. Karkee $\mathrm{R}$, Lee $\mathrm{AH}$, Binns $\mathrm{CW}$. Why women do not utilize maternity services in Nepal: a literature review. WHO South-East Asia J Public Health. 2013;2(34):135-41.

11. Mezmur M, Navaneetham K, Letamo G, Bariagaber H. Individual, household and contextual factors associated with skilled delivery care in Ethiopia: evidence from Ethiopian demographic and health surveys. PLoS One. 2017; 12(9):e0184688. https://www.ncbi.nlm.nih.gov/pmc/articles/PMC5598994/ pdf/pone.0184688.pdf.

12. Adu J, Tenkorang E, Banchani E, Allison J, Mulay S. The effects of individual and community-level factors on maternal health outcomes in GhanaD. PLoS One. 2018;13(11):e0207942. https://www.ncbi.n/m.nih.gov/pmc/articles/ PMC6264832/pdf/pone.0207942.pdf.

13. Adewuyi EO, Auta A, Khanal V, Olasunkanmi BD, Akuoko CP, Adefemi K, Tapshak SJ, Zhao Y. Prevalence and factors associated with underutilization of antenatal care services in Nigeria: a comparative study of rural and urban residences based on the 2013 Nigeria demographic and health survey. PLoS One. 2018;13(5):e0197324. https://www.ncbi.nlm.nih.gov/pmc/articles/ PMC5962076/pdf/pone.0197324.pdf.

14. Hagos S, Shaweno D, Assegid M, Mekonnen A, Afework MF, Ahmed S. Utilization of institutional delivery service at Wukro and Butajera districts in the northern and south Central Ethiopia. BMC Pregnancy and Childbirth. 2014;14:178. https://bmcpregnancychildbirth.biomedcentral.com/track/pdf/ 10.1186/1471-2393-14-178

15. Limenih MA, Endale Z, Dachew BA: Postnatal care service utilization and associated factors among women who gave birth in the last 12 months prior to the study in Debre Markos town, northwestern Ethiopia: a community-based cross-sectional study. Hindawi Publishing Corporation Int J Reproductive Medicine 2016:7095352. http://dx.doi.org/10.1155/2016/ 7095352.

16. Heyi WD, Deshi MM, Erana MG. Determinants of postnatal care service utilization in diga district, east wollega zone, wester Ethiopia: case-control study. EJRH. 2018;10(4):52-61.

17. Dahiru T, Oche OM. Determinants of antenatal care, institutional delivery and postnatal care services utilization in Nigeria Pan African. Medical Journal. 2015;21:321 310.11604/pamj.12015.11621.11321.16527.

18. Dickson KS, Amu H. Determinants of skilled birth attendance in the northern parts of Ghana. In: Hindawi Advances in Public Health. 2017:9102808. https:// doi.org/10.1155/2017/9102808.

19. Iyaniwura CA, Yussuf Q. Utilization of antenatal care and delivery services in Sagamu, South Western Nigeria Afr. J Reprod Health. 2009;13(3):111-22.

20. Vidler M, Ramadurg U, Charantimath U, Katageri G, Karadiguddi C, Sawchuck D, Qureshi R, Dharamsi S, Joshi A, Dadelszen Pv et al: Utilization of maternal health care services and their determinants in Karnataka state, India. Reproductive Health 2016, 13(Sppl 1):37; DOI 10.1186/s12978-1201610138-12978.

21. Machira K, Palamuleni M. Women's perspectives on quality of maternal health care services in Malawi. Int J Women's Health. 2018;10:25-34.
22. Kucho B, Mekonnen N. Delivery at home and associated factors among women in child bearing age, who gave birth in the preceding two years in Zala Woreda, southern Ethiopia. J Public Health Epidemiol. 2017;9(6):177-88 110.5897/JPHE2017.0921.

23. Amdemichael R, Tafa M, Fekadu H. Maternal satisfaction with the delivery Services in Assela Hospital, Arsi zone, Oromia region. Gynecol Obstet (Sunnyvale). 2014;4:12 https://doi.org/10.4172/2161-0932.1000257.

24. Asefa A, Bekele D. Status of respectful and non-abusive care during facilitybased childbirth in a hospital and health centers in Addis Ababa, Ethiopia. Reproductive Health. 2015;12:33 https://doi.org/10.1186/s12978-1201510024-12979.

25. Demas T, Getinet T, Bekele D, Gishu T, Birara M, Abeje Y. Women's satisfaction with intrapartum care in St Paul's hospital millennium medical college Addis Ababa Ethiopia: a crosssectional study. BMC Pregnancy and Childbirth. 2017:17:253 DOl 210.1186/s12884-12017-11428-z.

26. Melese T, Gebrehiwot Y, Bisetegne D, Habte D: Pan African Medical Journal Assessment of client satisfaction in labor and delivery services at a maternity referral hospital in Ethiopia 2014, 17:76 doi:10.11604/pamj.12014. 11617.11676.13189.

27. Bhattacherjee S, Datta S, Saha JB, Chakraborty M. Maternal health care services utilization in tea gardens of Darjeeling. India JBasic and Clin Reproductive Sciences. 2013(2, 2):77-84. https://doi.org/10.4103/2278-4960X. 118645.

28. Rutaremwa G, Wandera SO, Jhamba T, Akiror E, Kiconco A. Determinants of maternal health services utilization in Uganda. BMC Health Serv Res. 2015; 15:271 DOI 210.1186/s12913-12015-10943-12918.

29. Perkins J, Capello C, Vilgrain C, Groth L, Billoir H, Santarelli C. Determinants of low maternal and newborn health service utilization in Haiti: a community-based cross- sectional study. J Women's Health, Issues Care. 2017:6:1. https://doi.org/10.4172/2325-9795.1000258.

30. Deepak C, Jauhari N, Dhungana $H$. A study on utilization of maternal health services and factors influencing the utilization in urban slums of Lucknow. Int J Med Public Health. 2018;8(2):77-81.

31. Yaya S, Uthman OA, Amouzou A, Ekholuenetale M, Bishwajit G. Inequalities in maternal health care utilization in Benin: a population based crosssectional study. BMC Pregnancy and Childbirth. 2018;18:194. https://doi.org/ 10.1186/s12884-018-1846-6.

32. Terye ND: Multilevel modeling of utilization of maternal health Care Services in Ethiopia Ee-JRIF 2015, 7(1):1-19.

33. WHO: WHO recommendations on antenatal care for a positive pregnancy experience. Geneva: World Health Organization, 20 Avenue Appia, 1211 Geneva 27, Switzerland; 2016.

34. Munjial M, Kaushik P, Agnihotri S. A comparative analysis of institutional and noninstitutional deliveries in a village of Punjab. Health and Population: Perspectives and Issues. 2009;32(3):131-40.

35. Akunga D, Menya D, Kabue M. Determinants of postnatal care use in Kenya African. Popul Stud. 2014;28(3):1447-59.

36. Bogale D, Markos D. Knowledge of obstetric danger signs among child bearing age women in Goba district, Ethiopia: a cross-sectional study. BMC Pregnancy and Childbirth. 2015;15:77 https://doi.org/10.1186/s12884-1201510508-12881.

37. Salam RA, Mansoor T, Mallick D, Lassi ZS, Das JK, Bhutta ZA. Essential childbirth and postnatal interventions for improved maternal and neonatal health. Reprod Health. 2014;11(S3). http://www.reproductive-health-journal. com/content/11/S1/S3

38. Lawn JE, Blencowe H, Oza S, You D, Lee AC, Waiswa P, Lalli M, Zq B, Barros AJ, Christian P, et al. Progress, priorities, and potential beyond survival. Lancet. 2014; https://doi.org/10.1016/S0140-6736(1014)60496-60497.

39. Doku DT, Neupane S. Survival analysis of the association between antenatal care attendance and neonatal mortality in 57 low- and middle-income countries. Int J Epidemiol. 2017;46(5):1668-77 1610.1093/ije/dyx1125.

40. Kifle D, Azale T, Gelaw YA, Melsew YA. Maternal health care service seeking behaviors and associated factors among women in rural Haramaya District, eastern Ethiopia: a triangulated community-based cross-sectional study. Reprod Health. 2017;14:6 https://doi.org/10.1186/s12978-12016-10270-12975.

41. Getachew T, Abajobir AA, Aychiluhim M. Focused antenatal care service utilization and associated factors in Dejen and Aneded districts, Northwest Ethiopia. Primary Health Care. 2014;4(4) https://doi.org/10.4172/2167-1079. 1000170.

42. Tura G. Antenatal care service utilization and associated factors in Meteke zone, Northwest Ethiopia. Ethiop J Health Sci. 2009;19(2):111-9. 
43. Fawole AO, Okunlola MA, Adekunle AO. Clients' perceptions of the quality of antenatal care. J Nat Med Association. 2008;100(9):1052-8.

44. Ayele DZ, Belayihun B, Teji K, Ayana DA. Factors affecting utilization of maternal health Care Services in Kombolcha District, eastern Hararghe zone, Oromia regional state, eastern Ethiopia. Hindawi Publishing Corporation. 2014; https://doi.org/10.1155/2014/917058.

45. Abosse Z, Woldie M, Ololo S. Factors influencing antenatal care service utilization in Hadiya zone. Ethiop J Health Sci. 2010(2, 2):75-82.

46. Fikre AA, Demissie M. Prevalence of institutional delivery and associated factors in Dodota Woreda (district), Oromia regional state, Ethiopia. Reprod Health. 2012;9:33. http:/www.reproductive-health-journal.com/content/9/1/33

47. Tadele N, Lamaro T. Utilization of institutional delivery service and associated factors in bench Maji zone, Southwest Ethiopia: community based, cross sectional study. BMC Health Serv Res. 2017;17:101 DOI 110. 1186/s12913-12017-12057-y.

48. Odo DB, Shifti DM. Institutional delivery service utilization and associated factors among child bearing age women in Goba Woreda, Ethiopia. Journal of Gynecology and Obstetrics. 2014;2(4):63-70. https://doi.org/10.11648/j. jgo.20140204.20140214.

49. EIPH/FMOH, WHO: Health Data Quality Review: System Assessment an data Verication Addis Ababa, Ethiopia; 2016.

50. Belachew T, Taye A, Belachew T. Postnatal care service utilization and associated factors among mothers in Lemo Woreda, Ethiopia. J Women's Health Care. 2016;5. https://doi.org/10.4172/2167-0420.1000318:3.

51. Workineh YG, Hailu DA. Factors affecting utilization of postnatal Care Service in Amhara Region, Jabitena District, Ethiopia. Science Journal of Public Health. 2014;2(3):169-76 110.11648/j.sph.20140203.20140215.

52. Rwabufigiri BN, Mukamurigo J, Thomson DR, Hedt-Gautier BL, Semasaka aJPS. Factors associated with postnatal care utilisation in Rwanda: A secondary analysis of 2010 Demographic and Health Survey data. BMC Pregnancy and Childbirth. 2016;16(122). https://doi.org/10.1186/s1288412016-10913-12880.

53. Nzioki JM, Onyango RO, Ombaka JH. Socio-demographic factors influencing maternal and child health service utilization in Mwingi; a rural semi-Arid District in Kenya. Am J Public Health Research. 2015;3(1):21-30. https://doi. org/10.12691/ajphr-12693-12691-12694.

54. Adhikari C, Yadav RK, Timilshina P, Ojha R, Gaire D, Ghimire A: Proportion and factors affecting for post-natal care utilization in developing countries: A systematic review JMMIHS 2016, 1(2):1-6; ISSN: 2091-1041.

55. Floyd L, Coulter N, Asamoah S, Agyare-Asante R. Women's views and experience of their maternity care at a referral hospital in Ghana. AJM. 2014; 8(4):168-75

Ready to submit your research? Choose BMC and benefit from:

- fast, convenient online submission

- thorough peer review by experienced researchers in your field

- rapid publication on acceptance

- support for research data, including large and complex data types

- gold Open Access which fosters wider collaboration and increased citations

- maximum visibility for your research: over $100 \mathrm{M}$ website views per year

At BMC, research is always in progress.

Learn more biomedcentral.com/submissions 